\title{
miRNA-99b-3p functions as a potential tumor suppressor by targeting glycogen synthase kinase- $3 \beta$ in oral squamous cell carcinoma Tca-8113 cells
}

\author{
KANG HE ${ }^{1,3^{*}}$, DONGDONG TONG ${ }^{3 *}$, SI ZHANG $^{4}$, DONGHUI CAI ${ }^{3}$, LUMIN WANG $^{3}$, YANG YANG $^{3}$, \\ LING GAO ${ }^{2}$, SU'E CHANG $^{3}$, BO GUO $^{3}$, TUSHENG SONG ${ }^{3}, \mathrm{ANG} \mathrm{LI}^{1}$ and CHEN HUANG
}

Departments of ${ }^{1}$ Periodontology and ${ }^{2}$ Oral Maxillofacial Surgery, Stomatology Hospital of Xi'an Jiaotong University College of Medicine, Xi'an, Shaanxi 710004; ${ }^{3}$ Department of Genetics and Molecular Biology, Key Laboratory of Environment and Genes Related to Diseases, College of Medicine, Xi'an Jiaotong University, Xi'an, Shaanxi 710061; ${ }^{4}$ Department of Stomatology, First Affiliated Hospital of Xi'an Medical University, Xi'an, Shaanxi 710077, P.R. China

Received June 23,2015; Accepted August 17, 2015

DOI: $10.3892 /$ ijo. 2015.3135

\begin{abstract}
Dysregulation of microRNAs (miRNAs) has been associated with carcinogenesis in oral squamous cell carcinoma (OSCC). In the present study, we investigated the expression and function of miR-99b-3p in human OSCC. We found that the expression levels of miR-99b-3p decreased in 21 clinical OSCC samples (84\%). Furthermore, ectopic expression of miR-99b-3p inhibited OSCC cell proliferation by downregulating glycogen synthase kinase-3 $\beta$ (GSK3 $\beta$ ), an miR-99b-3p' target gene, at the mRNA and protein levels, both in vitro and in vivo. Moreover, the silencing of GSK3 $\beta$ recapitulated the cellular and molecular effects in a similar manner to the overexpression of miR-99b-3p, which included inhibition of OSCC cell proliferation and suppression of p65 (RelA) and $\mathrm{G}_{1}$ regulators (cyclin $\mathrm{D}_{1}, \mathrm{CDK} 4$ and CDK6) in vitro. Our data suggest that miR-99b-3p functions as a tumor suppressor in OSCC via GSK3 $\beta$ downregulation.
\end{abstract}

\section{Introduction}

OSCC is the 6th most common malignancy and is a major cause of cancer morbidity and mortality (1). OSCC accounts

Correspondence to: Professor Ang Li, Department of Periodontology, Stomatology Hospital, College of Medicine, Xi'an Jiaotong University, Xi'an, Shaanxi 710004, P.R. China

E-mail: drliangyj@gmail.com

Professor Chen Huang, Department of Genetics and Molecular Biology, Xi'an Jiaotong, University School of Medicine, 76 Yan Ta West Road, Xi'an, Shaanxi 710061, P.R. China

E-mail: hchen@mail.xjtu.edu.cn

* Contributed equally

Key words: oral squamous cell carcinoma, miR-99b-3p, GSK3 $\beta$, $\mathrm{p} 65$, proliferation for $\sim 90 \%$ of all oral cancers. Despite the advances in diagnosis and treatment, only $\sim 50 \%$ of the patients with OSCC survived for 5 years in the past decade (2). Oral carcinogenesis arises as a result of the activation of some oncogenes or the inactivation of tumor suppressor genes (3). Growing evidence has shown that non-coding small RNAs play an important role in OSCC pathogenesis, which provides new insights into the treatment of this cancer.

MicroRNAs (miRNAs) are an abundant class of short RNAs, which are 19-24 nucleotides in length; miRNAs were shown to affect complementarity by binding at the $3^{\prime}$ untranslated region (UTR) of target genes, resulting in degradation of target mRNAs and inhibition of translation (4). Many studies have shown that miRNA dysregulation occurs in various human diseases, especially cancer. miRNAs are involved in crucial cellular processes, including development, differentiation, proliferation and apoptosis (5). Several studies have suggested that dysregulation of miRNAs, including miR-29b, miR-9, miR-29a, is related with OSCC initiation and development (6-8).

miRNA-99b is a member of the miR-125a let-7e cluster that is involved in a series of cellular activities such as cell proliferation, differentiation and invasion (9-11). Recent studies have shown that miR-125a expression decreased in non-small cell lung cancer and breast cancer $(12,13)$. Previously, it has been found that miR-99b-3p is expressed in the Helicobacter pylori infection-dependent gastric cancer (14) and that the miR-99b-3p is considered to be a new tumor marker. This predicts the relapse-free survival in patients with the follicular variant of papillary thyroid carcinoma (15). However, the function of miR-99b-3p in cancer, particularly in the pathogenesis of OSCC, has not yet been reported.

The aim of the present study was to determine the role of miR-99b-3p in OSCC. The potential mechanisms underlying the regulation of the biological behavior of OSCC by $\mathrm{miR}-99 \mathrm{~b}-3 \mathrm{p}$ were also investigated. Our findings will contribute to understanding of the function of miR-99b-3p in the progression of OSCC. 
Table I. Relationship between clinicopathological factors and miR-99b-3p expression levels.

\begin{tabular}{|c|c|c|c|c|}
\hline \multirow[b]{2}{*}{ Characteristics } & \multirow{2}{*}{$\begin{array}{l}\text { No. of } \\
\text { cases }\end{array}$} & \multicolumn{2}{|c|}{$\begin{array}{l}\text { miR-99b-3p } \\
\text { expression }\end{array}$} & \multirow[b]{2}{*}{ P-value } \\
\hline & & High & Low & \\
\hline Age (years) & & & & 0.260 \\
\hline$\geq 60$ & 9 & 0 & 9 & \\
\hline$<60$ & 16 & 4 & 12 & \\
\hline Gender & & & & 0.656 \\
\hline Male & 15 & 2 & 13 & \\
\hline Female & 10 & 2 & 8 & \\
\hline Histology & & & & 0.357 \\
\hline Well & 17 & 3 & 14 & \\
\hline Moderate & 5 & 2 & 3 & \\
\hline Poor & 3 & 0 & 3 & \\
\hline pTNM stage & & & & 0.552 \\
\hline I & 9 & 1 & 8 & \\
\hline II & 5 & 1 & 4 & \\
\hline III & 2 & 1 & 1 & \\
\hline IV & 9 & 1 & 8 & \\
\hline
\end{tabular}

\section{Materials and methods}

Tissue samples. Formaldehyde-fixed, paraffin-embedded (FFPE) tissue samples were obtained from surgical specimens from 25 patients (15 male, 10 female, 59.07 \pm 10.69 and $53.62 \pm 15.29$ years of age, respectively) diagnosed with OSCC, between January 1987 and June 2011 at the Stomatological Hospital, College of Medicine, Xi'an Jiaotong University (Table I). Before the operation none of the patients had received radiotherapy or chemotherapy. The non-tumor tissues were taken more than $2 \mathrm{~cm}$ from the tumor to be used as controls and were confirmed by an experienced pathologist. The study was approved by our institutional review board, and an informed consent was given by all the patients.

Cell lines. Tca-8113, established in Ninth People's Hospital, Shanghai Second Medical University in 1981, was purchased from the Shanghai GeneChem Co., Ltd. (Shanghai, China) and grown in RPMI-1640 medium (PAA Laboratories $\mathrm{GmbH}$ ) supplement with $10 \%$ FBS (PAA Laboratories $\mathrm{GmbH}$ ) at $37^{\circ} \mathrm{C}$ in a humidified atmosphere of $95 \%$ air and $5 \% \mathrm{CO}_{2}$.

Quantitative real-time reverse transcription PCR. Total RNA from Tca-8113 cells and prepared tissues sample was isolated using the TRIzol reagent (Invitrogen) and RecoverAll ${ }^{\mathrm{TM}}$ Total Nucleic Acid Isolation kit (Ambion, Austin, TX, USA) according to the manufacturer's protocol. The cDNA was synthesized according to the manufacturer's protocol (MBI Fermentas). Quantitative real-time PCR (qRT-PCR) was performed using a Maxima SYBR-Green qPCR Master Mixes (MBI Fermentas) and PCR-specific amplification was conducted in the Roche LightCycler ${ }^{\circledR} 480$ II real-time PCR. The relative expression of genes (miR-99b-3p, U6, GSK3B and $\beta$-actin) was calculated with the $2^{-\Delta \Delta C t}$ method (16). The primers used are: qRT-PCR, miR-99b-3p-F5'-ATCC AGTGCGTGTCGTG-3', miR-99b-3p-R5'-TGCTCAAGCT CGTGTCTGT-3'; GSK3 $\beta$-F5'-CCTCTGGCTACCATCCT TATTC-3', GSK3 $\beta$-R5'-TTATTGGTCTGTCCACGGT CTC-3'; U6-F5'-TGCGGGTGCTCGCTTCGGCAGC-3', U6-R5'-CCAGTGCAGGGTCCGAGGT-3'; $\beta$-actin-F5'-CG TGACATTAAGGAGAAGCTG-3', $\beta$-actin-R5'-CTAGAAG CATTTGCGGTGGAC-3'.

Construction of expression plasmids. The miR-99b-3p expression vector (pre-miR-99b) and control vector were constructed with synthetic oligonucleotides and cloned between the EcoRI and HindIII sites of the pcDNA6.2-GW/EmGFP vector (Invitrogen): pre-miR-99b-F'-AATTCGGCACCCACCCG TAGAACCGACCTTGCGGGGCCTTCGCCGCACACAAG CTCGTGTCTGTGGGTCCGTGTCA-3'; R-5'-AGCTTGAC ACGGACCCACAGACACGAGCTTGTGTGCGGCGAAGG CCCCGCAAGGTCGGTTCTACGGGTGGGTGCCG-3'. Primers contained 5'EcoRI and 3'HindIII restriction sites to facilitate cloning into the vector. The inhibitor of miR-99b-3p and small interfering RNA (siRNA) targeting GSK3 $\beta$ were purchased from GenePharma. The siRNA-GSK3B target sequence GAUGAGGUCUAUCUUAAUC (nt:1353-1371) (17).

Bioinformatic analysis. The information of human miR-99b-3p was registered, and obtained from miRBase (http://www. miRBase.org/). We used the publicly available programs: RegRNA(http://regrna.mbc.nctu.edu.tw/), miRanda(http:// www.microrna.org/) to acquire the prediction of miRNA targets.

Stable transfection of miR-99b expression vector. The day before transfection, Tca- 8113 cells were plated in antibioticfree medium at $\sim 25 \%$. Pre-miR-99b and control vector were transfected into Tca-8113 cells using LipoFiter ${ }^{\mathrm{TM}}$ (Hanbio, Shanghai, China) in accordance with the manufacturer's procedure, cultured by selection with $8 \mu \mathrm{g} / \mathrm{ml}$ blasticidin (Invitrogen) containing medium for 2 weeks. Single cell clones were picked and cultured in medium (RPIM-1640) containing $4 \mu \mathrm{g} / \mathrm{ml}$ blasticidin for further study. The expression level of miR-99b-3p in transfected Tca-8113 cells was identified by quantitative real-time PCR after further selection and expansion.

Lentivirus infection. Lentivirus Luc was synthesized by Shanghai GeneChem. Stability enhanced pre-miR-99b Tca-8113 cells were infected by lentiviruses according to the manufacturer's protocol.

Cell proliferation assay. The Tca- 8113 cells (5,000 cells/ well) were seeded into 96 -well plates with $200 \mu \mathrm{l}$ of 1640 medium, and cultured 24-72 $\mathrm{h}$ after transfecting with vector control, pre-miR-99b expression vector, inhibitor control, miR-99b-3p inhibitor, siRNA control and GSK3 $\beta$ siRNA. Cells washed with warm DMEM and MTT (Sigma) working solution were incubated at $37^{\circ} \mathrm{C}$ for $4 \mathrm{~h}$. Using acidic isopropanol (0.04 $\mathrm{M} \mathrm{HCl}$ in absolute isopropanol) solubilized the 
converted dye. Absorbance of the converted dye was measured at a wavelength of $490 \mathrm{~nm}$ with FLUOstar Optima (BMG).

Cell cycle analysis. The Tca- 8113 cells at $1 \times 10^{6}$ cells/well were cultured in 12-well plates in triplicate and transfected with DNA vectors or siRNAs for $24 \mathrm{~h}$. Cells were harvested by trypsinization, then washed in PBS, and fixed in ice-cold ethanol at $4^{\circ} \mathrm{C}$ overnight. Then cells were washed twice in PBS and incubated in $1 \mathrm{ml}$ of staining solution $(20 \mathrm{mg} / \mathrm{ml}$ propidium iodide and $10 \mathrm{U} / \mathrm{ml} \mathrm{RNaseA}$ ) for $30 \mathrm{~min}$ at room temperature. Cell cycle distribution was evaluated by fluorescence-activated cell sorting by flow cytometry (FACSort; Becton-Dickinson).

Dual luciferase assay. HEK293 cells were seeded in a 96-well plate at a density of $1 \times 10^{4}$ cells/well one day before transfection. miR-99b-3p expression vector was co-transfected with wild or mutated 3'-UTR of GSK3 $\beta$ reporter constructs and a blank pmirGLO Dual-luciferase as a positive control group. After $24 \mathrm{~h}$, the Dual-luciferase reporter assay system (Promega) was used to measure the reporter activity according to the manufacturer's protocol.

Colony formation assay. The transfected Tca- 8113 cells were seeded into 6-well plates at a density of 1,000/well, incubated for two weeks. Colonies were then stained with $0.1 \%$ crystal violet for $30 \mathrm{~min}$, counted and normalized to the control group.

Western blot analysis. All Tca-8113 cells or tissue were lysed using RIPA buffer, supplemented with protease inhibitor (Invitrogen). Protein was then separated with 10\% SDS polyacrylamide gels, and electrophoretically transferred to polyvinylidene difluoride membrane (Millipore). The membrane was incubated with primary antibodies to GSK3 $\beta$ (Abcam; antibody dilutions: 1:1,500), p65, cyclin $\mathrm{D}_{1}$, CDK4, CDK6, Lamin $B_{1}$ (Proteintech, antibody dilutions: 1:1,000), $\beta$-actin antibody (CST, antibody dilutions: 1:2,000). The blots were scanned and the band density was measured on Quantity One imaging software.

Immunohistochemistry. Immunohistochemistry (IHC) was performed according to the methods previously described (18). The tissue sections were incubated in the primary antibodies overnight. Staining intensity was assessed by Leica Q550 image analysis system.

In vivo tumor xenograft model. Six-week-old male nude mice (BALB/c-nude) were used to analyse tumorigenicity. Tca-8113 cells were stably tranfected with pre-miR-99b and control vector which were infected with LV-Luc and resuspended in PBS, then $1 \times 10^{7}$ cells were injected subcutaneously into both posterior flanks of nude mice. Tumor size was measured every 3 days. At 18 days after injection, mice from the pre-miR-99b group $(n=3)$ and control group $(n=3)$ were subjected in vivo to endpoint experiments, the bioluminescence images in vivo were obtained by the system of photobiology (Xenogen).

Statistical analysis. We repeated each experiment at least 3 times independently. Numercial data are presented as mean \pm SD. Differences between 2 groups were calculated with the Student's t-test (two-tailed). The associations between clinicopathological factors and miR-99b-3p levels were analyzed using the Chi-square test. $\mathrm{P}<0.05$ was considered to be significant.

\section{Results}

Aberrant miR-99b-3p expression in human OSCC. To validate the expression of miR-99b-3p in human OSCC, we analyzed the expression of miR-99b-3p in 25 paired human OSCC tissue samples and adjacent non-cancerous oral mucosa using real-time PCR. Compared with their peritumor counterparts, we observed significant downregulation of miR-99b-3p in $84 \%$ (21/25) of the OSCC samples (Fig. 1A). Moreover, miR-99b-3p was significantly downregulated in Tca-8113 cells compared with normal human oral epithelial cells (Fig. 1B). This indicated that the miR-99b-3p may play a role as a tumor suppressor in the OSCC. Therefore, we analyzed the relationship between miR-99b-3p levels and clinicopathological factors in OSCC samples (Table I). There was no significant difference between low expression of miR-99b-3p and clinicopathological factors such as age $(\mathrm{P}=0.260)$, gender $(\mathrm{P}=0.656)$, histology $(\mathrm{P}=0.357)$ and $\mathrm{pT}$ stage $(\mathrm{P}=0.552)$.

Overexpression of miR-99b-3p suppresses Tca-8113 cell growth and induces $G_{I}$-S arrest in vitro. To explore the role of miR-99b-3p in OSCC, Tca-8113 cells were transfected with an miR-99b precursor overexpression vector or negative controls. The efficiency of vector transfection was monitored with a GFP-label and an average of $70 \%$ efficiency was observed at a concentration of $100 \mathrm{nmol} / 1$ without causing obvious cell toxicity. qRT-PCR was performed to determine the expression levels of miR-99b-3p after transfection of the miR-99b-3p precursor construct vector. The results showed that the expression of miR-99b-3p in the pre-miR-99b-transfected cells was $\sim 8$-fold higher than that in the control vector-transfected cells (Fig. 1C). The MTT assay and colony formation assay indicated significant inhibition of cell growth and colony formation after pre-miR-99b transfection, as compared to that seen for cells transfected with the empty vector (Fig. 1D and $\mathrm{H}$ ). The next cell cycle experiment demonstrated that miR-99b-3p overexpression caused cell cycle arrest at $\mathrm{G}_{1}-\mathrm{S}$ in Tca- 8113 cells (Fig. 1F). To further explore the potential molecular mechanisms of miR-99b-3p-induced cell proliferation and cell cycle arrest, we analyzed the protein levels of related G1 regulators after miR-99b-3p overexpression in Tca- 8113 by using western blot analysis. Our results showed that miR-99b-3p expression may reduce the expression of cyclin $\mathrm{D}_{1}, \mathrm{CDK} 4$, and CDK6, which are the essential regulators of the $\mathrm{G}_{1}-\mathrm{S}$ phase transition (Fig. 1I).

Loss-of-function studies were also performed by using anti-miR-99b-3p oligonucleotides to silence the expression of miR-99b-3p (Fig. 1E, G and H). Unexpectedly, inhibition of miR-99b-3p could only slightly increase the expression of these proteins in Tca-8113 cells (Fig. 1I). The low expression of endogenous miR-99b-3p in Tca-8113 cells may account for this phenomenon. These results suggest that miR-99b-3p inhibits the proliferation of Tca- 8113 cells and arrests the cell cycle by controlling cell cycle-related gene expression. 

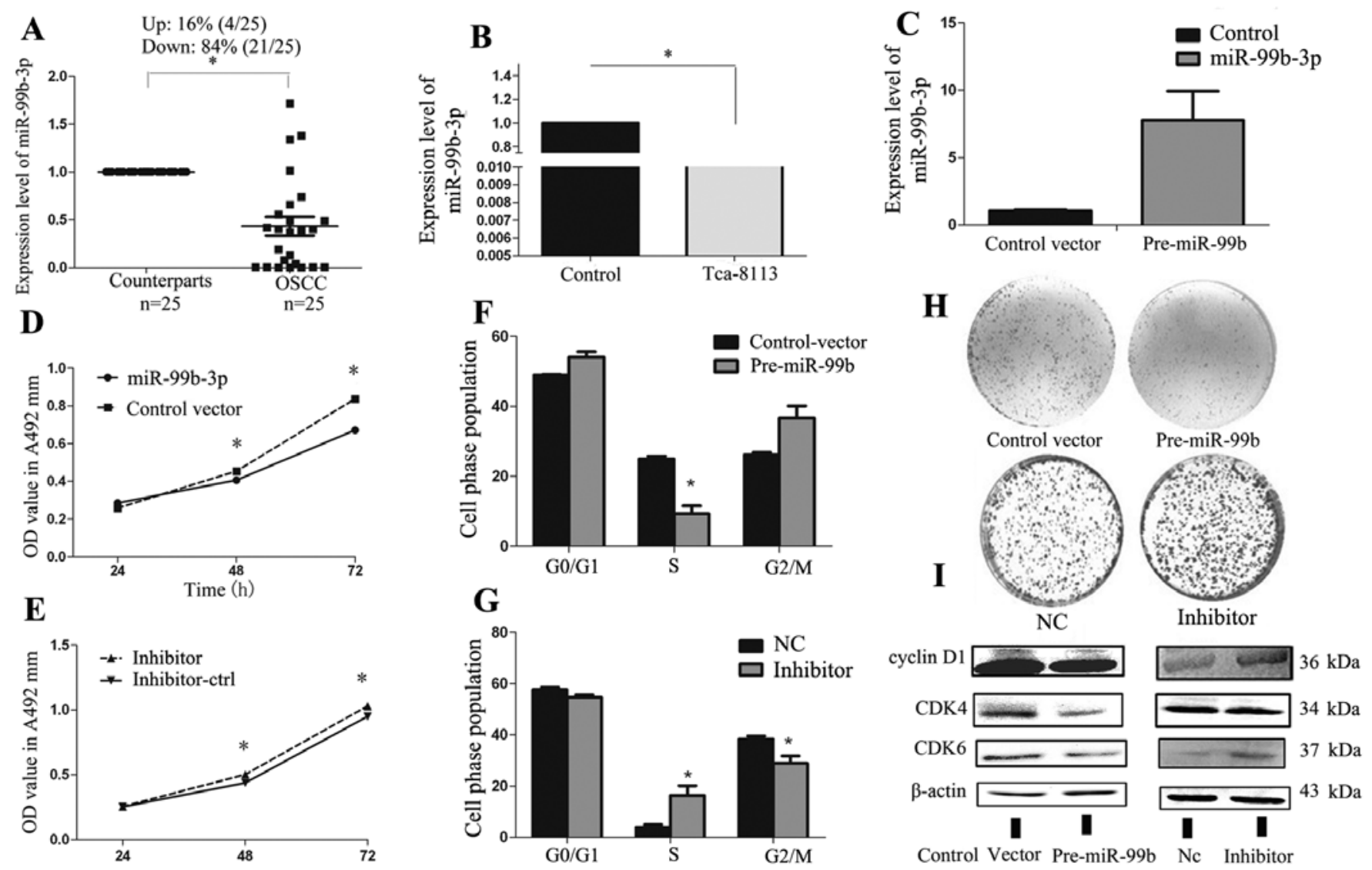

Figure 1. Low expression of miR-99b-3p in 25 oral squamous cell carcinoma (OSCC) tissue samples and OSCC cell line (Tca-8113) compared with noncancerous samples and normal human oral epithelial cells. Overexpression and inhibition of miR-99b-3p affect OSCC progression in vitro: (A) expression of miR-99b-3p in OSCC tissue samples (84\% OSCC tissue is upregulation), (B) expression of miR-99b-3p in Tca-8113 cell line. ("P<0.05, Student's t-test). (C) qRT-PCR analysis of miR-99b-3p in Tca-8113 cells transfected with pre-miR-99b overexpression construct and empty vector. (D and E) The effects of premiR-99b vector or miR-99b-3p inhibitor on Tca- 8113 cell proliferation were determined by MTT assay at 24,48 and $72 \mathrm{~h}$ after transfection with pre-miR-99b or miR-99b-3p inhibitor, with empty vector or ASO-NC, respectively. (F and G) Histogram represented the percentage of cells in $\mathrm{G}_{0}-\mathrm{G}_{1}, \mathrm{~S}$, and $\mathrm{G}_{2}-\mathrm{M}_{\mathrm{s}}$ cell cycle phases after transfection for $48 \mathrm{~h}$ based on the flow cytometric analysis. (H) Representative micrographs of crystal violet-stained cell colonies were analyzed by colony formation assay at day 14 after transfection. (I) Expression of the cell cycle regulators transfected by pre-miR-99b or miR-99b-3p inhibitor in Tca-8113 was analysis by western blot experiments.

GSK $3 \beta$ is a direct target gene of miR-99b-3p. We searched the bioinformatic databases RegRNA and miRanda, and identified a large number of potential target genes of miR-99b-3p. GSK $3 \beta$ was selected for further analysis among these candidate genes. As shown in Fig. 2A, the binding site at the GSK3 $\beta 3$ '-untranslated region (UTR) is displayed. To confirm whether miR-99b-3p directly targets GSK3 $\beta$, we constructed 3'UTR fragments of GSK3 $\beta$ (WT/MT) and a binding site for miR-99b-3p, which was subcloned into the pmirGLO Dualluciferase reporter vector. HEK293 cells were cotransfected with pre-miR-99b, pmirGLO control vector, and a reporter plasmid (GSK3 $\beta$ WT- or MT-3' UTR). Consequently, premiR-99b/GSK3 $\beta$ (WT)_UTR transfected cells showed significant reduction $(\sim 40 \%)$ of luciferase activity (Fig. $2 B$ ), which suggested that miR-99b-3p could suppress gene expression through its binding sequences at the 3'UTR of GSK3 3 .

GSK $3 \beta$ is dysregulated in OSCC cancer cell lines and tissues. We used the Oncomine cancer microarray database, which enabled multiple comparisons among different studies, to analyze the expression profile of GSK $3 \beta$ mRNA in OSCC tissue. In 6 studies, OSCC tissue samples had higher GSK3 $\beta$ expression than normal tissue. These results showed that
GSK3 $\beta$ expression was correlated with OSCC progress (Table II) (19-24). The protein level of GSK3 $\beta$ was examined in paired OSCC tissues from 3 cases by western blot analysis and immunohistochemistry. As Fig. 2D and E show, GSK $3 \beta$ protein levels were significantly higher in OSCC tissue than in paired adjacent tissues. Compared to the findings for control vector-transfected cells, significant reduction in GSK $3 \beta$ and p65 expression was observed in Tca-8113 cells when transfected with miR-99b-3p precursor (Fig. 2C, G and H). These results indicated that miR-99b-3p might directly target the $3^{\prime}$ UTR of GSK $3 \beta$ mRNA and inhibit GSK3 $\beta$ translation. Alteration in the p65 protein expression level occurred in both the cell cytoplasm and the nucleus.

Silencing of GSK3 $\beta$ suppresses Tca-8113 cell growth and induces $G_{I}-S$ arrest, similarly to miR-99b-3p. Next, we used RNA interference (RNAi) methods to silence GSK3 $\beta$ expression to determine whether GSK3 $\beta$ was involved in the antitumor effects of miR-99b-3p. GSK3 $\beta$ could be specifically knocked down by siRNA (Fig. 3A and E). Moreover, silencing of GSK $3 \beta$ suppressed the growth and proliferation of Tca- 8113 cells and induced $\mathrm{G}_{1}-\mathrm{S}$ arrest, which is similar to the role of miR-99b-3p in Tca-8113 cells (Fig. 3B-D). Next, we analyzed 
A

miR-99b-3p: 3. eeCUG-GGUGUCUGUGCUCGAaC 5 "

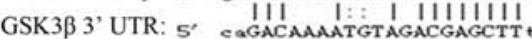

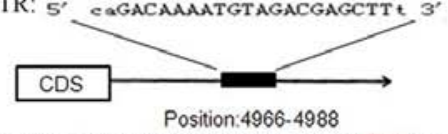

PGLO-GSK3ß-3'UTR-WT:TCGAGAATCAGACAAAATGTAGACGAGCTTTTTAG PGLO-GSK3ß-3'UTR-MT:TCGAGAATCAGACAAAATGTAGAGCGCTTTTAG

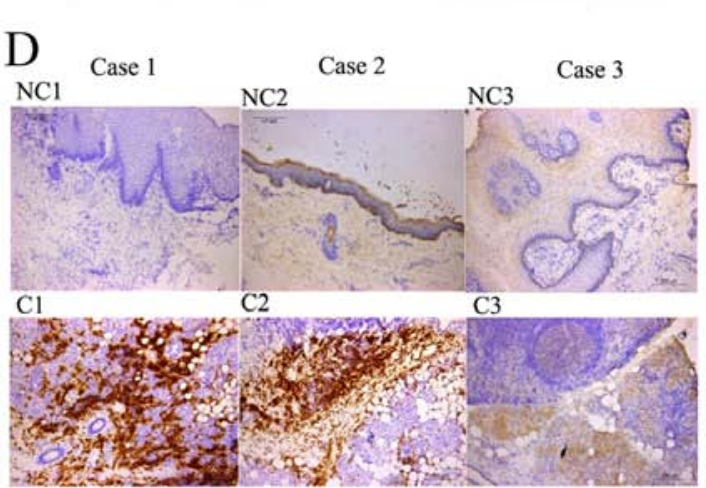

$\mathrm{E}$

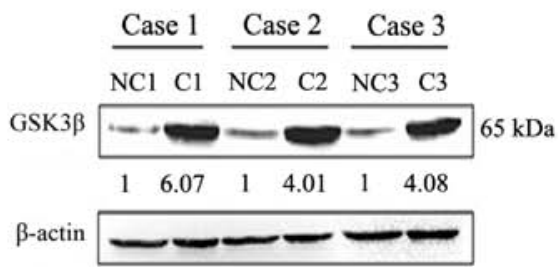

B

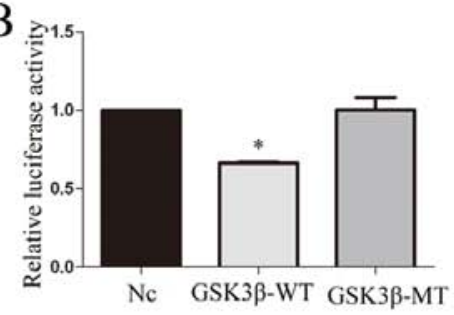

$\mathrm{F}$

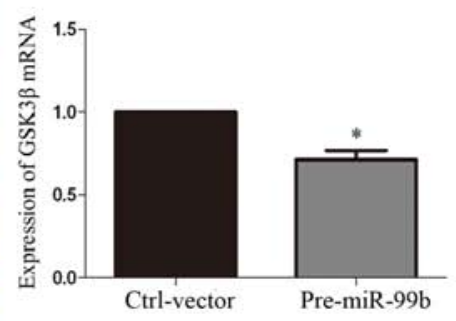

$\mathrm{H}$

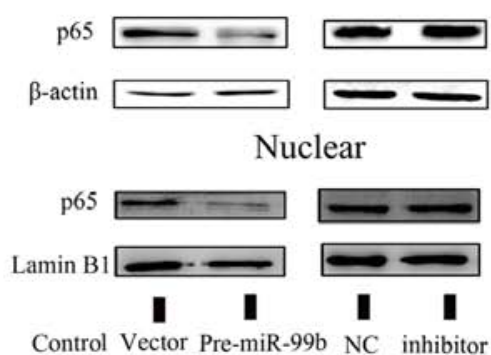

C

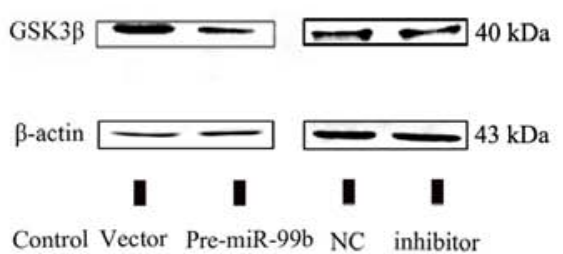

G

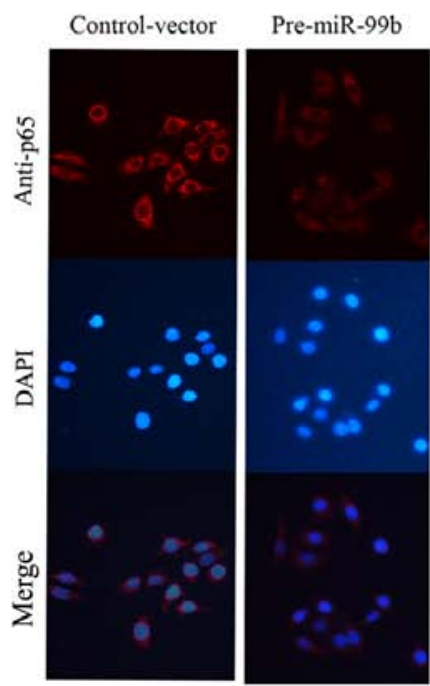

Figure 2. GSK3 $\beta$ is experimentally validated as a direct target of miR-99b-3p in Tca-8113 cell line. (A) Wild-type or mutant miR-99b target sequences of the GSK33 3'UTR. (B) Luciferase assay in HEK293 cells. Pre-miR-99b was cotransfected with target gene reporter construct (WT or MT version of pGLO constructs) or NS-control. Relative repression of luciferase expression was standardized to $\beta$-gal signal. Luciferase activity in pGLO-GSK3 $\beta$-WT group was statistically decreased following ectopic expression of miR-99b-3p. (C) GSK3 3 protein expression level in Tca-8113 was measured by western blot analysis $48 \mathrm{~h}$ after transfection with pre-miR-99b vector or miR-99b-3p inhibitor. (D and E) Expression of GSK3 $\beta$ was determined by western blot analysis and immunohistochemical in OSCC tissues and their corresponding non-tumorous oral mucosa. (F) qRT-PCR were performed to determine the expression level of GSK $3 \beta$ after transfection of pre-miR-99b vector ("P $<0.05$, Student's t-test). ( $\mathrm{G}$ and H) The protein expression level of $\mathrm{p} 65$ was detected by immunofluorescence staining and western blot analysis after transfection with pre-miR-99b vector for $48 \mathrm{~h}$.

Table II. Expression of GSK3 $\beta$ in human normal mouth mucosa tissue and OSCC carcinoma.

\begin{tabular}{lcccc}
\hline Cancer vs. normal (sample number) & Correlation (up/down) & Fold change & P-value & Ref. \\
\hline Tongue squamous cell carcinoma (31) vs. tongue (26) & $\uparrow$ & 1.727 & $6.19 \mathrm{E}-10$ & $(19)$ \\
Tongue squamous cell carcinoma (31) vs. tongue (26) & $\uparrow$ & 1.947 & $6.47 \mathrm{E}-9$ & $(20)$ \\
Tongue squamous cell carcinoma (26) vs. tongue (12) & $\uparrow$ & 1.980 & $3.76 \mathrm{E}-5$ & $(21)$ \\
Tongue squamous cell carcinoma (3) vs. mucosa (22) & $\uparrow$ & 1.259 & 0.049 & $(22)$ \\
Oral cavity squamous cell carcinoma (4) vs. squamous cell (16) & $\uparrow$ & 1.341 & 0.031 & $(23)$ \\
Oral cavity squamous cell carcinoma (57) vs. oral cavity (22) & $\uparrow$ & 1.197 & 0.002 & $(24)$
\end{tabular}

Data were provided by the cancer microarray database Oncomine (www.oncomine.org).

protein levels of related $G_{1}$ regulators after silencing the GSK3 $\beta$ in Tca-8113 cells in western blot analysis. As shown in Fig. 3E, the expression of $\mathrm{NF}-\kappa \mathrm{B}$ (p65) was suppressed by si-GSK3 $\beta$ (Fig. 3E and F). For cell cycle regulation, si-GSK3 $\beta$ may reduce the expression of cyclin $\mathrm{D}_{1}, \mathrm{CDK} 4$, and CDK6, which are the essential regulators of the $\mathrm{G}_{1}-\mathrm{S}$ phase transition.
Thus, we speculate that GSK3 $\beta$ and p65 dysregulation in OSCC may promote OSCC tumorigenesis.

miR-99b-3p inhibits OSCC tumor growth in vivo. To further confirm the growth-inhibitory function of miR-99b-3p in OSCC, we tested the effects of miR-99b-3p on tumor growth 


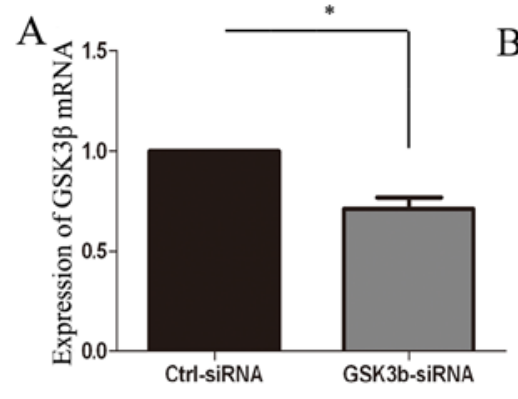

D

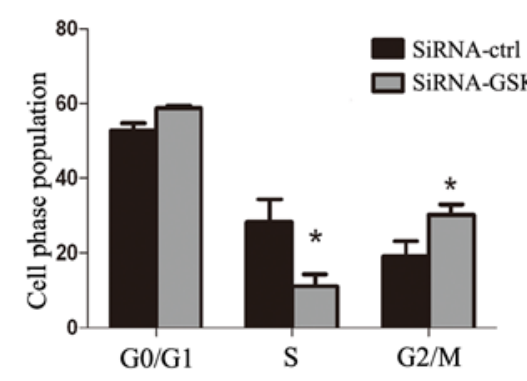

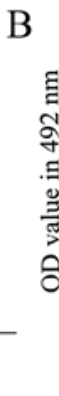

E

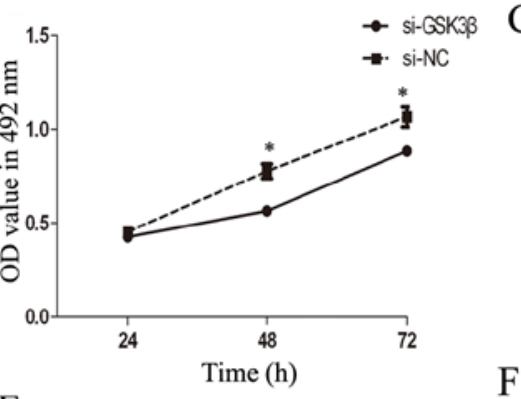

F

C
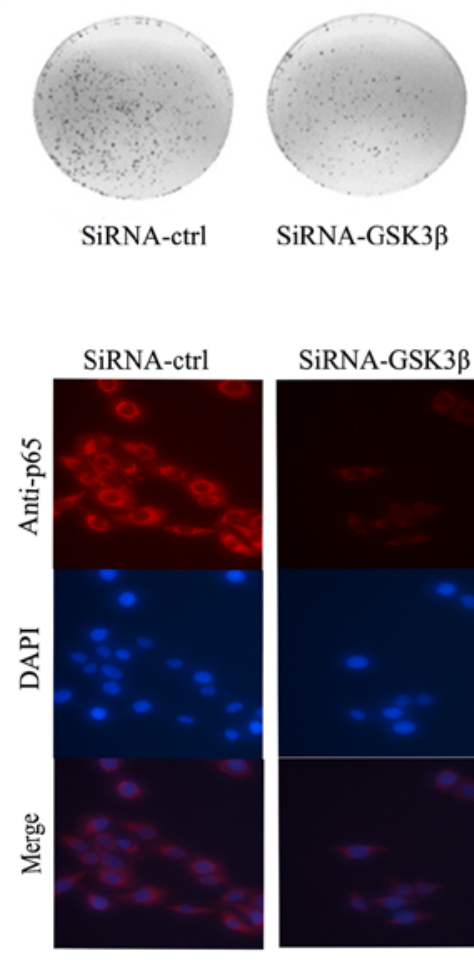

SiRNA-GSK3 3

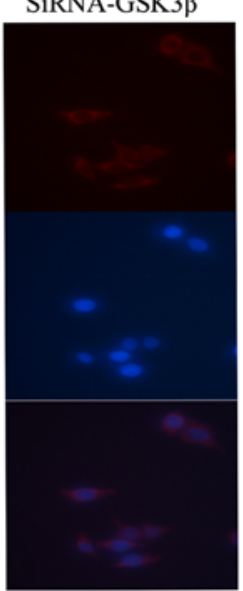

Figure 3. Silencing of GSK3 $\beta$ suppresses Tca- 8113 growth and induces $\mathrm{G}_{1}-\mathrm{S}$ arrest. (A) qRT-PCR was performed to determine the expression level of GSK3 $\beta$ after transfection with GSK3 $\beta$ siRNA. (B-D) MTT assay/cell cycle/ clone formation were performed to determine the impact of Tca-8113 cells treated with siRNA of GSK3 $\beta$. (E and F) Expression analysis for GSK3 $\beta$ and p65 proteins expression in Tca-8113 cells at $48 \mathrm{~h}$ after transfected with control siRNA or GSK3 $\beta$ siRNA by western blot analysis and immunofluorescence staining. $\beta$-actin and lamin B1 was used as a housekeeping control. Statistical differences were analyzed with the Wilcoxon signed-rank test ( ${ }^{*} \mathrm{P}<0.05$; Student's t-test).

in an in vivo xenograft model. Cells from stably transfected cell lines developed from miR-99b-3p- and miR-controltransfected Tca-8113 cells were injected subcutaneously into the posterior flank of the same nude mice. After injection, palpable tumors developed at 1 week and were measured every 3 days. As shown in Fig. 4A-C, tumor growth was significantly suppressed by pre-miR-99b-treated cells as compared to that seen for control vector-treated cells, during the experiments. This trend was confirmed by the size and weight of tumors excised from the animals. On day 18 , the average volume of pre-miR-99b-treated tumors was lesser than that for the control group. The average tumor weights for the control and the miR-99b-3p groups on day 27 were $1.35 \mathrm{~g}$ and $0.84 \mathrm{~g}$, respectively. Next, we assessed the expression levels of miR-99b-3p and GSK3 $\beta$ in the tumor tissues by qRT-PCR and western blot analyses. We found that the tumors transfected with premiR-99b had an 4 -fold increase in miR-99b-3p, as compared to the control group (Fig. 4D). The in vivo data showed that the expression level of NF- $\kappa \mathrm{B}$ (p65), cyclin $\mathrm{D}_{1}, \mathrm{CDK} 4$ and CDK6 proteins all decreased in pre-miR-99b-treated tumors, which was consistent with the in vitro data (Fig. 4F). These data indicated that miR-99b-3p expression is capable of inhibiting tumor growth by inhibiting GSK3 $\beta$ expression levels in vivo.

\section{Discussion}

During the past 10 years, dysregulation of miRNAs has been reported to be a common event that controls cell proliferation (25), cell cycle (26) and metastasis (27) in OSCC. The miR-99b gene, located on chromosome 19q13.41, produces two mature forms (miR-99b-3p and miR-99b-5p). Some recent reports suggested that miR-99b-5p could influence the sensitivity of pancreatic cancer cells to radiotherapy and suppress the growth rate of lung cancer $(28,29)$. Very little research has been focused on miR-99b-3p, except for the study by Chang et al (14) and Dettmer et al (15) showing that miRNA-99b-3p is correlated with papillary thyroid carcinoma and $H$. pylori-positive gastric cancer. In the present study, we found that miR-99b-3p was commonly downregulated in OSCC tissue samples and Tca- 8113 cells, indicating that miR-99b-3p might be a novel tumor suppressor miRNA. In a series of cell experiments, gain and loss of function studies showed that miR-99b-3p was able to inhibit cell proliferation by arresting cells in the $\mathrm{G}_{1}-\mathrm{S}$ transition in vitro. The luciferase assay showed that GSK3 $\beta$ is a direct target of miR-99b-3p in OSCC.

Oncomine algorithms were utilized in a preliminary study to confirm higher expression of GSK $3 \beta$ in OSCC as compared to that in normal mucosa, which concurred with our experimental result. GSK $3 \beta$ is an isoform splice variant of GSK3, which has been reported to phosphorylate over a dozen transcription factors (30). GSK3 $\beta$ is recognized as an important component in a large number of cellular processes and diseases. The exact physiological effect of GSK3 $\beta$ in cancer is unclear, but accumulated data have shown that GSK3 $\beta$ plays an important role in tumorigenesis. Dysregulation of 

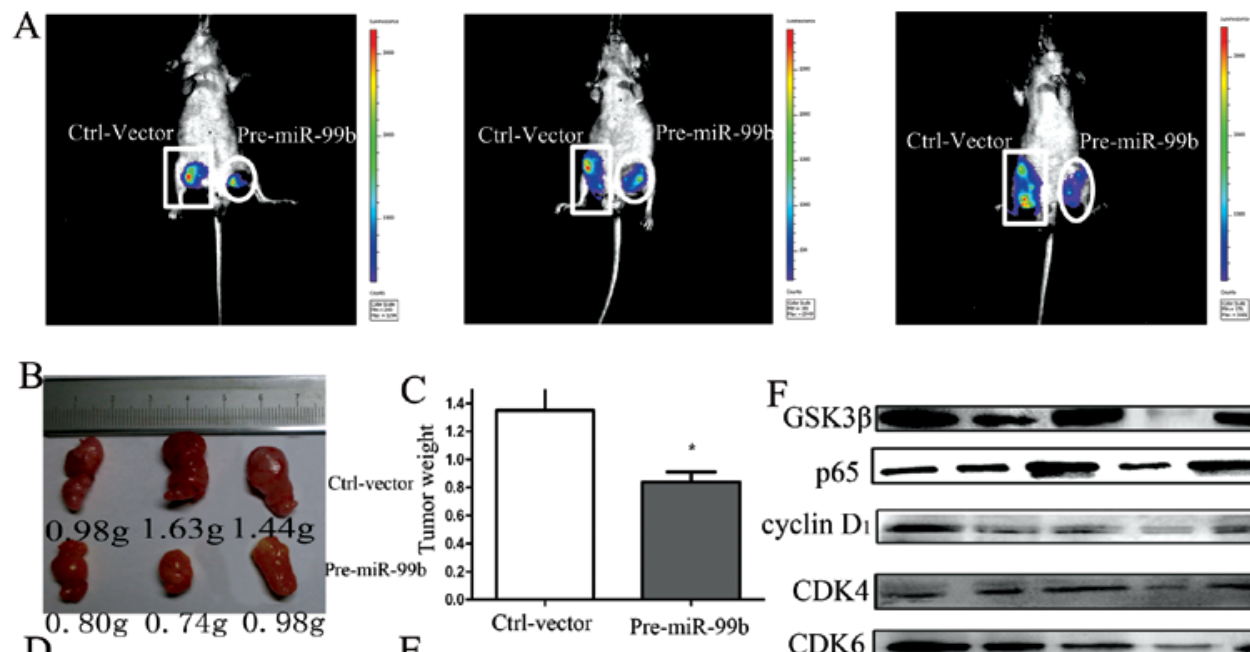

$\mathrm{D}$

E

F

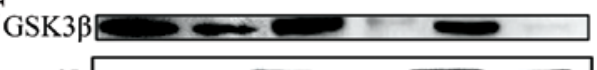

p65

cyclin D

$\mathrm{CDK} 4$

CDK6
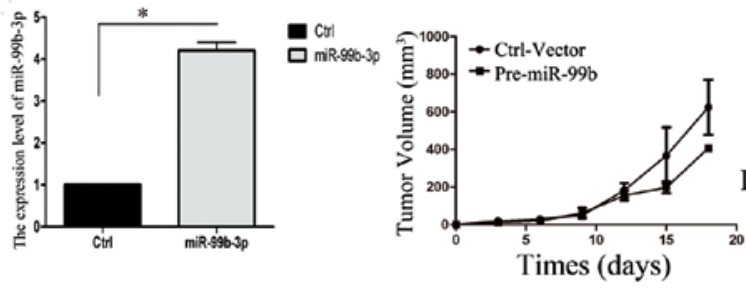

$\beta$-actin

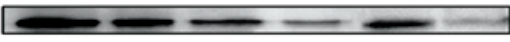

\section{Nuclear fraction}

p65

Lamin $\mathrm{B}_{1}$

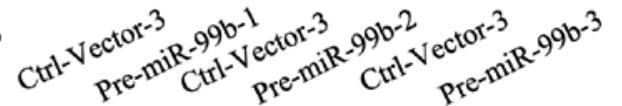

Figure 4. miR-99b-3p inhibits Tca-8113 cells progression in vivo. (A) At day 18, small animal imaging analysis was used to assess the tumor volume in situ during the tumor development. (A) The flanks of nude mice were injected with NC-transfected (left flank) and miR-99b-transfected cells (right flank) in 3 nude mice, respectively. (B) The gross morphology of tumors showed the morphology of mice injected with miR-99b and miR-ctrl. (C) At day 18 after the first measure, the mice were anesthetized and sacrificed at the experimental endpoint and tumors infected with pre-miR-99b and control vector were weighted. (D) The expression levels of miR-99b-3p were detected by qRT-PCR analysis in the tumor tissues from the nude mice. (E) Tumor growth curves. (F) Overexpression of miR-99b-3p in the xenografts decreased the GSK3 $\beta$ protein level and subsequently reduced the expression of p65 and $\mathrm{G}_{1}$ regulators as determined using western blot analysis.

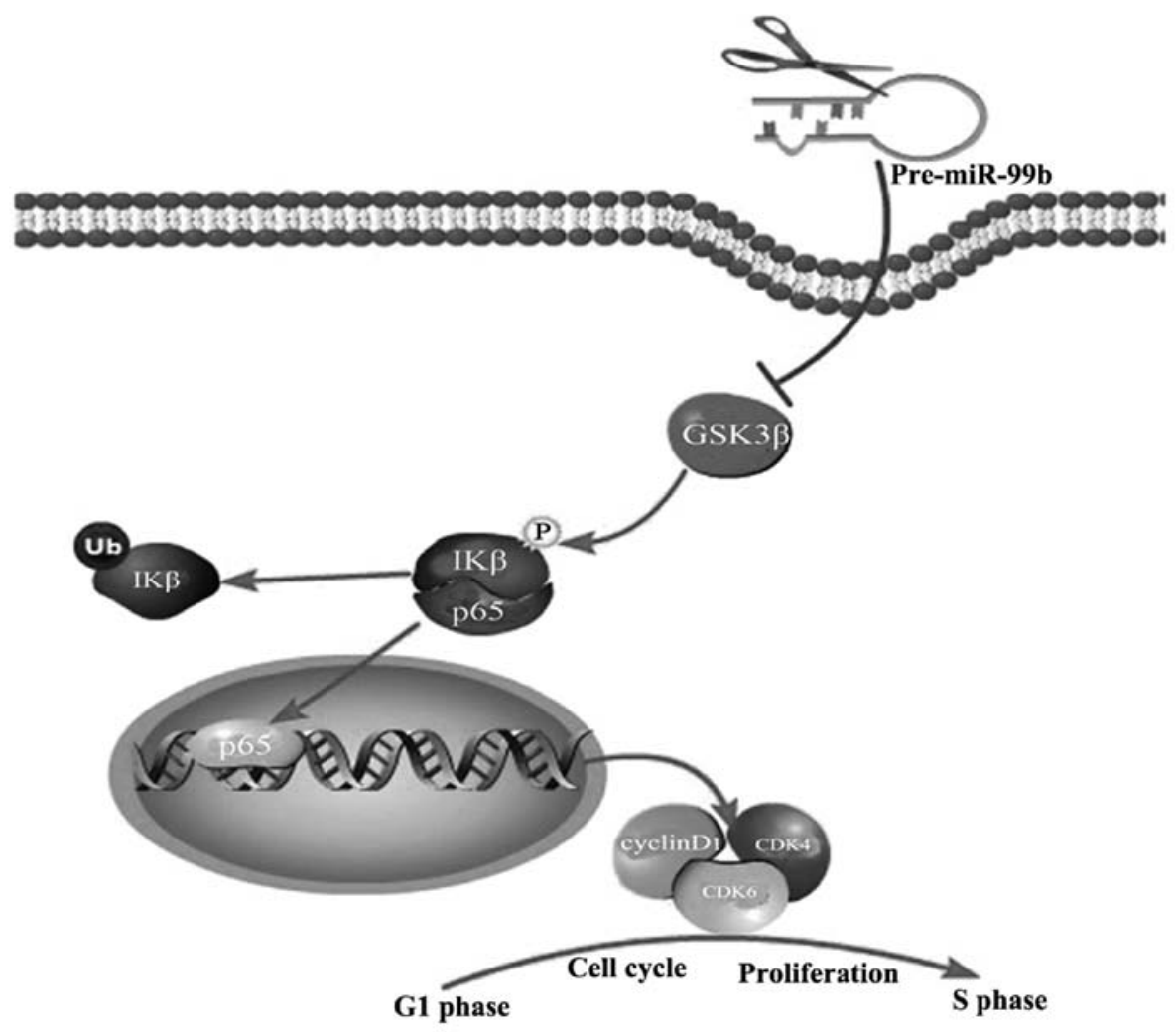

Figure 5. Proposed model for the effects of miR-99b-3p-mediated GSK $3 \beta$ on the NF- $\kappa$ B pathways, and suppression of proliferation. GSK $3 \beta$ is important for the activation of direct I $\mathrm{KB}$ phosphorylation and degradation. p65(RelA) translocates into the nuclei to activate the transcription of cyclin $\mathrm{D}_{1}$, CDK4 and CDK6. As a result of the cyclin activation, the NF- $\mathrm{\kappa B}$ pathway is involved in promoting proliferation. 
GSK3 $\beta$, that is, either overexpression (31) or inhibition $(32,33)$ by a pharmacological inhibitor, is a frequent oncogenic event in human mechanisms. Several studies support that GSK3 $\beta$ functions as a tumor suppressor. The tumor suppressor action is exemplified by GSK3 $\beta$-mediated phosphorylation and subsequent degradation of $\beta$-catenin, which is a transcriptional co-activator that often promotes cellular proliferation (34). However, some studies suggest that GSK $3 \beta$ may promote tumorigenesis. The expression of GSK3 $\beta$ is upregulated in multiple cancers, including ovarian, pancreatic and colorectal cancers $(31,33,35)$. GSK3 $\beta$ regulates cell proliferation via activation of $\mathrm{NF}-\kappa \mathrm{B}$-dependent gene transcription in ovarian and pancreatic cancers (31). p65(RelA) is one of the subunits of $N F-\kappa B$, which is capable of mediating interactions with basal transcription factors and cofactors (36). p65 is typically sequestered in the cell cytoplasm by I $\kappa$ B proteins (37). It has been reported that GSK3 $\beta$ is a key component involved in inducing activation of the IKK complex and degradation of $\mathrm{I} \kappa \mathrm{B}$ in pancreatic cancer cells (32). After degradation of I $\mathrm{B}$ proteins, the released p65 proteins are further activated, and they translocate to the nucleus where they bind to specific DNA sequences and promote transcription of target genes $(38,39)$. p65 is necessary for the positive regulation of gene expression through cyclin $\mathrm{D}_{1}, \mathrm{CDK} 4$ and CDK6 (40-42). These 3 proteins could be considered as active cell cycle regulators. When quiescent cells are stimulated to enter the cell cycle, expression of cyclin $D_{1}$ promotes progression through the $G_{1}$ phase through association and activation of CDK4 and CDK6 (43). In our research, GSK3 $\beta$ expression was inversely correlated with miR-99b-3p. GSK3 $\beta$ inhibition by siRNA had the same effect on OSCC cell growth as overexpression of miR-99b-3p. Our data are consistent with recent studies on the regulation of cell proliferation by GSK $3 \beta$ though an NF- $\kappa \mathrm{B}$-dependent pathway, as we observed that the manipulation of GSK3 $\beta$ expression may result in suppression of p65 and decrease in the expression of cell cycle proteins (cyclin $\mathrm{D}_{1}, \mathrm{CDK} 4$ and CDK6).

Our findings suggest that miR-99b-3p may function as a cell cycle suppressor by targeting GSK $3 \beta$ in Tca- 8113 cells. The above results suggest that miR-99b-3p may act as a therapeutic intervention in Tca-8113 cells. Further animal studies indicate that miR-99b-3p can suppress the growth of OSCC xenografts in nude mice and the expression of GSK $3 \beta$ in tumors. Our observations that miR-99b-3p targets GSK $3 \beta$ and suppresses Tca-8113 cells growth in vitro are also supported by the in vivo studies.

In conclusion, to the best of our knowledge, the present study is the first to report downregulation of miR-99b-3p in Tca- 8113 cells and clinical samples. Moreover, we explored the role of miR-99b-3p, its target gene GSK3 $\beta$, and their potential molecular mechanisms in suppressing tumorigenicity of OSCC. These data suggest that miR-99b-3p may be a novel tumor suppressor that inhibits the growth of OSCC through $\mathrm{NF}-\kappa \mathrm{B}$ signaling pathways by targeting GSK3$\beta$ (Fig. 5). Thus, miR-99b-3p could provide a potential therapeutic strategy for the treatment of OSCC in the future.

\section{Acknowledgements}

The present study was financially supported by the Key Science and Technology Major Program of Shaanxi Province, China
(2010ZDKG-50), the National Natural Science Foundation of China (81171398 and 31100921), and The Program for Chang Jiang Scholars and Innovative Research Team in University (PCSIRT; 1171).

\section{References}

1. Parkin DM, Bray F, Ferlay $\mathrm{J}$ and Pisani P: Estimating the world cancer burden: Globocan 2000. Int J Cancer 94: 153-156, 2001.

2. Funk GF, Karnell LH, Robinson RA, Zhen WK, Trask DK and Hoffman HT: Presentation, treatment, and outcome of oral cavity cancer: A National Cancer Data Base report. Head Neck 24: 165-180, 2002.

3. Croce CM: Oncogenes and cancer. N Engl J Med 358: 502-511, 2008.

4. Bartel DP: MicroRNAs: Genomics, biogenesis, mechanism, and function. Cell 116: 281-297, 2004.

5. Karp X and Ambros V: Developmental biology. Encountering microRNAs in cell fate signaling. Science 310: 1288-1289, 2005.

6. Yang CN, Deng YT, Tang JY, Cheng SJ, Chen ST, Li YJ, Wu TS, Yang MH, Lin BR, Kuo MY, et al: MicroRNA-29b regulates migration in oral squamous cell carcinoma and its clinical significance. Oral Oncol 51: 170-177, 2015.

7. Yu T, Liu K, Wu Y, Fan J, Chen J, Li C, Yang Q and Wang Z: MicroRNA-9 inhibits the proliferation of oral squamous cell carcinoma cells by suppressing expression of CXCR 4 via the Wnt/ $\beta$-catenin signaling pathway. Oncogene 33: 5017-5027, 2014.

8. Lu L, Xue X, Lan J, Gao Y, Xiong Z, Zhang H, Jiang W, Song W and Zhi Q: MicroRNA-29a upregulates MMP2 in oral squamous cell carcinoma to promote cancer invasion and anti-apoptosis. Biomed Pharmacother 68: 13-19, 2014.

9. Mitra D, Das PM, Huynh FC and Jones FE: Jumonji/ARID1 B (JARID1B) protein promotes breast tumor cell cycle progression through epigenetic repression of microRNA let-7e. J Biol Chem 286: 40531-40535, 2011

10. Zhu WY, Luo B, An JY, He JY, Chen DD, Xu LY, Huang YY, Liu XG, Le HB and Zhang YK: Differential expression of miR-125a-5p and let-7e predicts the progression and prognosis of non-small cell lung cancer. Cancer Invest 32: 394-401, 2014.

11. Ninio-Many L, Grossman H, Levi M, Zilber S, Tsarfaty I, Shomron N, Tuvar A, Chuderland D, Stemmer SM, Ben-Aharon I, et al: MicroRNA miR-125a-3p modulates molecular pathway of motility and migration in prostate cancer cells. Oncoscience 1: 250-261, 2014.

12. Jiang L, Huang Q, Zhang S, Zhang Q, Chang J, Qiu X and Wang E: Hsa-miR-125a-3p and hsa-miR-125a-5p are downregulated in non-small cell lung cancer and have inverse effects on invasion and migration of lung cancer cells. BMC Cancer 10: $318,2010$.

13. O'Day E and Lal A: MicroRNAs and their target gene networks in breast cancer. Breast Cancer Res 12: 201, 2010.

14. Chang H, Kim N, Park JH, Nam RH, Choi YJ, Lee HS, Yoon H, Shin CM, Park YS, Kim JM, et al: Different microRNA expression levels in gastric cancer depending on Helicobacter pylori infection. Gut Liver 9: 188-196, 2014.

15. Dettmer M, Perren A, Moch H, Komminoth P, Nikiforov YE and Nikiforova MN: Comprehensive MicroRNA expression profiling identifies novel markers in follicular variant of papillary thyroid carcinoma. Thyroid 23: 1383-1389, 2013.

16. Livak KJ and Schmittgen TD: Analysis of relative gene expression data using real-time quantitative PCR and the $2(-\Delta \Delta \mathrm{C}(\mathrm{T}))$ method. Methods 25: 402-408, 2001.

17. Grassilli E, Narloch R, Federzoni E, Ianzano L, Pisano F, Giovannoni R, Romano G, Masiero L, Leone BE, Bonin S, et al: Inhibition of GSK3B bypass drug resistance of p53-null colon carcinomas by enabling necroptosis in response to chemotherapy. Clin Cancer Res 19: 3820-3831, 2013.

18. Lai KW, Koh KX, Loh M, Tada K, Subramaniam MM, Lim XY, Vaithilingam A, Salto-Tellez M, Iacopetta B, Ito Y, et al; Singapore Gastric Cancer Consortium: MicroRNA-130b regulates the tumour suppressor RUNX3 in gastric cancer. Eur J Cancer 46: 1456-1463, 2010.

19. Talbot SG, Estilo C, Maghami E, Sarkaria IS, Pham DK, O-charoenrat P, Socci ND, Ngai I, Carlson D, Ghossein R, et al: Gene expression profiling allows distinction between primary and metastatic squamous cell carcinomas in the lung. Cancer Res 65: 3063-3071, 2005. 
20. Estilo CL, O-charoenrat P, Talbot S, Socci ND, Carlson DL, Ghossein R, Williams T, Yonekawa Y, Ramanathan Y, Boyle JO, et al: Oral tongue cancer gene expression profiling: Identification of novel potential prognosticators by oligonucleotide microarray analysis. BMC Cancer 9: 11, 2009.

21. Ye H, Yu T, Temam S, Ziober BL, Wang J, Schwartz JL, Mao L, Wong DT and Zhou X: Transcriptomic dissection of tongue squamous cell carcinoma. BMC Genomics 9: 69, 2008.

22. Kuriakose MA, Chen WT, He ZM, Sikora AG, Zhang P, Zhang ZY, Qiu WL, Hsu DF, McMunn-Coffran C, Brown SM, et al: Selection and validation of differentially expressed genes in head and neck cancer. Cell Mol Life Sci 61: 1372-1383, 2004.

23. Toruner GA, Ulger C, Alkan M, Galante AT, Rinaggio J, Wilk R, Tian B, Soteropoulos P, Hameed MR, Schwalb MN, et al: Association between gene expression profile and tumor invasion in oral squamous cell carcinoma. Cancer Genet Cytogenet 154: 27-35, 2004.

24. Peng CH, Liao CT, Peng SC, Chen YJ, Cheng AJ, Juang JL, Tsai CY, Chen TC, Chuang YJ, Tang CY, et al: A novel molecular signature identified by systems genetics approach predicts prognosis in oral squamous cell carcinoma. PLoS One 6: e23452, 2011.

25. Tiwari A, Shivananda S, Gopinath KS and Kumar A: MicroRNA-125a reduces proliferation and invasion of oral squamous cell carcinoma cells by targeting estrogen-related receptor $\alpha$ : Implications for cancer therapeutics. J Biol Chem 289: 32276-32290, 2014.

26. Shao Y, Qu Y, Dang S, Yao B and Ji M: MiR-145 inhibits oral squamous cell carcinoma (OSCC) cell growth by targeting c-Myc and Cdk6. Cancer Cell Int 13: 51, 2013.

27. Liu C, Wang Z, Wang Y and Gu W: MiR-338 suppresses the growth and metastasis of OSCC cells by targeting NRP1. Mol Cell Biochem 398: 115-122, 2015.

28. Kang J, Lee SY, Lee SY, Kim YJ, Park JY, Kwon SJ, Na MJ, Lee EJ, Jeon HS and Son JW: microRNA-99b acts as a tumor suppressor in non-small cell lung cancer by directly targeting fibroblast growth factor receptor 3. Exp Ther Med 3: 149-153, 2012.

29. Wei F, Liu Y, Guo Y, Xiang A, Wang G, Xue X and Lu Z: miR-99b-targeted mTOR induction contributes to irradiation resistance in pancreatic cancer. Mol Cancer 12: 81, 2013.

30. Jope RS and Johnson GV: The glamour and gloom of glycogen synthase kinase-3. Trends Biochem Sci 29: 95-102, 2004

31. Cao Q, Lu X and Feng YJ: Glycogen synthase kinase-3 $\beta$ positively regulates the proliferation of human ovarian cancer cells. Cell Res 16: 671-677, 2006.
32. Ougolkov AV, Fernandez-Zapico ME, Savoy DN, Urrutia RA and Billadeau DD: Glycogen synthase kinase-3beta participates in nuclear factor kappaB-mediated gene transcription and cell survival in pancreatic cancer cells. Cancer Res 65: 2076-2081, 2005.

33. Ougolkov AV, Fernandez-Zapico ME, Bilim VN, Smyrk TC, Chari ST and Billadeau DD: Aberrant nuclear accumulation of glycogen synthase kinase-3beta in human pancreatic cancer: Association with kinase activity and tumor dedifferentiation. Clin Cancer Res 12: 5074-5081, 2006.

34. Polakis P: The many ways of Wnt in cancer. Curr Opin Genet Dev 17: 45-51, 2007.

35. Kang T, Wei Y, Honaker Y, Yamaguchi H, Appella E, Hung MC and Piwnica-Worms H: GSK-3 $\beta$ targets Cdc25A for ubiquitinmediated proteolysis, and GSK-3 $\beta$ inactivation correlates with Cdc25A overproduction in human cancers. Cancer Cell 13: 36-47, 2008.

36. Perkins ND: The diverse and complex roles of NF- $\kappa B$ subunits in cancer. Nat Rev Cancer 12: 121-132, 2012.

37. Johnson J, Shi Z, Liu Y and Stack MS: Inhibitors of NF-kappaB reverse cellular invasion and target gene upregulation in an experimental model of aggressive oral squamous cell carcinoma. Oral Oncol 50: 468-477, 2014.

38. Hayden MS and Ghosh S: Shared principles in NF-kappaB signaling. Cell 132: 344-362, 2008.

39. Takada Y, Ichikawa H, Pataer A, Swisher S and Aggarwal BB: Genetic deletion of PKR abrogates TNF-induced activation of IkappaBalpha kinase, JNK, Akt and cell proliferation but potentiates p44/p42 MAPK and p38 MAPK activation. Oncogene 26: 1201-1212, 2007.

40. Wang L, Kang F, Li J, Zhang J and Shan B: Overexpression of p65 attenuates celecoxib-induced cell death in MDA-MB-231 human breast cancer cell line. Cancer Cell Int 13: 14, 2013.

41. Tran KQ, Tin AS and Firestone GL: Artemisinin triggers a G1 cell cycle arrest of human Ishikawa endometrial cancer cells and inhibits cyclin-dependent kinase- 4 promoter activity and expression by disrupting nuclear factor- $\mathrm{kB}$ transcriptional signaling. Anticancer Drugs 25: 270-281, 2014.

42. Iwanaga R, Ozono E, Fujisawa J, Ikeda MA, Okamura N, Huang Y and Ohtani K: Activation of the cyclin D2 and cdk6 genes through NF-kappaB is critical for cell-cycle progression induced by HTLV-I Tax. Oncogene 27: 5635-5642, 2008.

43. Ho A and Dowdy SF: Regulation of G(1) cell-cycle progression by oncogenes and tumor suppressor genes. Curr Opin Genet Dev 12: 47-52, 2002 . 